\title{
ESTRATEGIAS Y PRÁCTICAS TURÍSTICAS EN UNA CIUDAD PATRIMONIO DE LA HUMANIDAD, TOLEDO*
}

\author{
M. Antono Zárate Martín \\ Dpto. de Geografía - Facultad de Geografía e Historia de la UNED \\ C/Senda del Rey, 7, 28040 Madrid \\ mzarate@geo.uned.es
}

\begin{abstract}
Resumen: El turismo es una actividad presente en Toledo desde fechas muy tempranas, entre otras razones por las abundantes referencias a lo largo de la historia sobre su singularidad cultural, monumental y paisajistica. La declaración de esta ciudad como "Conjunto Histórico Artístico" en 1940 y su calificación como "Ciudad Patrimonio de la Humanidad" en 1986 han contribuido a difundir aún más su imagen turística.

En la actualidad, actores públicos y privados promueven estrategias turísticas que promocionan nuevos productos, entre ellos los que buscan la participación activa de los visitantes y los que se dirigen al mundo de la empresa y de los negocios para superar la tradicional vinculación de esta actividad con la historia y los monumentos. Se trata de políticas turísticas que buscan el equilibrio entre las ventajas de la proximidad a Madrid y la excesiva dependencia que esta realidad origina.
\end{abstract}

Palabras clave: Turismo cultural, turismo de empresa, actores del turismo, infraestructuras de acogida, flujos turísticos

\begin{abstract}
The tourism is a present activity in Toledo from very early dates, among other reasons for the abundant references along the history on its cultural, monumental and landscape singularity. The declaration of this city as "Historical Artistic Set" in 1940 and its qualification as "City Patrimony of the Humanity" in 1986 they have helped to spread furthermore his tourist image. At present, public and private actors promote tourist strategies that promote new products, among them those who look for the active participation of the visitors and those who go to the world of the company and of the business to overcome the traditional links of this activity with the history and the monuments. One treats as political tourist that they seek to establish a balance between the advantages of the proximity to Madrid and the excessive dependence that this reality originates.
\end{abstract}

Keywords: Cultural tourism, tourism of company, actors of the tourism, infrastructures of reception, tourist flows.

* Recibido: 12-03-07. Aceptado: 1-06-07. 


\section{Importancia creciente del turismo de ciudades}

Desde sus orígenes, el turismo es un fenómeno social ligada a las ciudades, si bien ha habido que esperar a la década de los 90 para que se pueda hablar con toda propiedad de un turismo atraído por los recursos de la ciudad, entre otras razones por las actividades que tienen lugar en su interior. A partir de esos años, el turismo urbano no cesa de aumentar su importancia desde el punto de vista económico en el seno de los mercados turísticos nacionales e internacionales. Y lo mismo sucede en cuanto a su creciente papel como elemento de la animación social para el conjunto de las ciudades, sobre todo si se tiene en cuenta que la fiesta y el espectáculo callejero interesan cada vez más no sólo a los residentes sino a los turistas. El éxito de las "Noches Blancas Europa" de París, Madrid, Roma, Bruselas y Riga, siguiendo una iniciativa surgida en París en 2002, es tan sólo algunos de los muchos ejemplos en este sentido.

La demanda del turismo urbano aumenta constantemente en todo el mundo. Así, el $93 \%$ de los japoneses son turistas urbanos, los norteamericanos sitúan también las ciudades entre sus destinos turísticos preferentes y los europeos no dejan de incrementar su interés por las ciudades. En España, el turismo urbano representa más del $30 \%$ de las estancias y del $40 \%$ del consumo turístico. En Francia, las ciudades generan el mayor consumo turístico, con 23,6 mil millones de curos en 2005, de los que el $60 \%$ corresponde a los turistas extranjeros. En un mundo cada vez más urbanizado, el turismo de ciudades refuerza en todas partes su protagonismo y actúa como expresión del dinamismo de los lugares, de desarrollo local y de transformación funcional e interacción social (Gravari-Barbas, 2006).

Las razones del aumento de la importancia del turismo urbano son muy variadas, pero destacan entre ellas indudablemente los cambios económicos y sociales que acompañan a la globalización y una revolución tecnológica que reduce las distancias, acorta los desplazamientos y rebaja los costes de los transportes. Las exigencias de mayores contactos personales inherentes a la nueva economía y la concentración de la actividad en las ciudades multiplican las necesidades de compartir actividades profesionales en otros lugares e, indirectamente, originan prácticas que nadie dudaría en calificar como turísticas. Conferencias, congresos exposiciones, reuniones de trabajo se complementan con prácticas típicamente turísticas como visitas a museos y monumentos, asistencia a espectáculos, frecuentación de restaurantes y espacios de ocio, y, por supuesto, todo ello repercute sobre la necesidad de ampliar las infraestructuras de acogida y de ocupación del tiempo libre (Dévé, 2003). De ese modo, para un sector considerable de la población, las fronteras entre lo que es propiamente turismo y lo que no lo es, se diluyen cada vez más. Y además, dentro de los flujos definidos convencionalmente como turísticos, la visita de ciudades adquiere un protagonismo creciente, no sólo por lo ya señalado sino también por motivos culturales y de cono- 
cimiento, ya que las urbes son los lugares que mejor expresan y recogen las huellas del pasado. A ello se añaden los efectos que resultan de la transformación reciente de la cultura en un fenómeno más de consumo de masas (museos, exposiciones y espectáculos actúan en todas las ciudades como elementos que atraen un número creciente de turistas y visitantes), y el afán de las personas por buscar señas de identidad en contraposición con los elementos homogeneizadores que la globalización y sus dinámicas imponen en todo el planeta.

Conscientes de su importancia económica y social, el turismo se ha convertido en tema prioritario de interés y de preocupación para los responsables de la gestión urbana (Violier, 1999). A diferencia de lo que sucedió hasta hace relativamente poco tiempo, hasta principios de la década de los 90, las administraciones locales desarrollan estrategias específicas de turismo que han evolucionado rápidamente: desde una primera etapa, en la que se centraban en la puesta en turismo del patrimonio histórico monumental y en el aprovechamiento de los recursos económicos y las oportunidades de negocios de las ciudades, a una segunda y actual etapa, en la que se apuesta, sin renunciar a los anteriores valores, por la ampliación de la oferta y la especialización de la demanda, siempre de la mano de un proceso de fragmentación, diversificación y tecnificación de la oferta turística que se ajusta a los desafíos de un mercado cada vez más exigente y que no deja de buscar nuevos nichos para el turismo, entre ellos el denominado "industrial o de visita de empresa" (Zárate, 2006). Se pasa así de la promoción y comercialización fragmentaria e individualizada de los recursos de la ciudad, considerados como excepcionales (monumentos y acontecimientos festivos), a una concepción de la ciudad como destino turístico compuesto por muchos recursos, productos y servicios turísticos e integrales.

Hoy, todas las aglomeraciones disponen de políticas turísticas específicas y el turismo constituye una de las preocupaciones principales de sus gestores públicos, si bien es cierto que siempre en estrecha relación con la posición que las ciudades ocupan en la jerarquía urbana y con el grado de especialización funcional que cada una de ellas detenta. En el caso de Toledo, dentro de una influencia directa de la capital de España que ya alcanza un radio de 100 kilómetros desde su interior, el turismo es indudablemente una de sus actividades más destacadas, con más de millón y medio de visitantes anuales en 2006. Para gestionar estos flujos, los actores públicos y privados de esta ciudad ponen en marcha estrategias turísticas que también se utilizan para mejorar infraestructuras, equipamientos y servicios urbanos. No obstante, como en todas las ciudades, estas mismas estrategias no pueden evitar los conflictos de intereses entre los propios actores del turismo y, especialmente, entre éstos y los residentes. Incluso, algunas de las contradicciones que originan son susceptibles de poner en peligro el crecimiento de este mismo sector de la economía local, sobre todo si se hacen entrar en juego consideraciones medioambientales y de sostenibilidad. 


\section{La práctica del turismo toledano}

La imagen de Toledo como destino turístico cultural de primera importancia se ha difundido por el mundo entero gracias a la abundancia de referencias literarias (Cervantes, Tirso de Molina, Maurice Barrès, Waldo Frank, Gregorio Marañón y tantos otros), a las numerosas representaciones a través del grabado y de la pintura (Anton Van den Wyngaerde, George Braun, Franz Hagenberg, El Greco, Roberts, A. Guesdon, Parcerisa, Genaro Pérez Villamil, Aureliano Beruete, Ignacio Zuloaga, etc.), a las descripciones en numerosas guías de viaje desde el siglo XIX e igualmente a haber servido como escenario de numerosas películas (Zárate, 1994). Del mismo modo, su temprana declaración como Conjunto Histórico-Artístico por el gobierno de España, por Decreto del Consejo de Ministros de 9 de marzo de 1940, a la vez que Santiago de Compostela, y al amparo de la ley de 13 de mayo de 1933, y su más reciente calificación como "Ciudad Patrimonio de la Humanidad" por la UNESCO, en 1986, han contribuido a reforzar sus atractivos sobre el turismo nacional e internacional (Zárate, 2000).

Con 114 Bienes de Interés Cultural pertenecientes a las culturas romana, visigoda, musulmana y cristiana, con unos paisajes urbanos singulares y un entorno protegido expresamente a través de "Zonas de Protección de Paisaje" definidas por las Instrucciones de la Dirección General de Bellas Artes desde 1965, respetadas por el Plan General de 1986, incorporadas al expediente de declaración de la ciudad como Patrimonio de la Humanidad instruido por la UNESCO en 1986, y actualizadas por el Título VII de las Ordenanzas del Plan Especial del Casco Histórico (17 de septiembre de 1998), Toledo es uno de los lugares obligados de visita turística para muchos españoles y para gran parte de los turistas y viajeros que llegan a Madrid desde otras regiones españolas y desde otros países. Se estima entre seiscientos mil y ochocientos mil los turistas registrados por la hostelería local y tres veces más, el número de personas que acuden anualmente a Toledo para visitar la ciudad, pasar el día en ella, recorrer sus calles, conocer sus monumentos, comer en alguno de sus restaurantes de calidad y asistir a acontecimientos sociales, especialmente bodas que muchos madrileños celebran en Toledo, atraỉdos por la belleza del entorno, la naturaleza del paisaje, el marco incomparable que proporcionan antiguos cigarrales transformados en hoteles y restaurantes, y por la propaganda de los empresarios del sector.

Tradicionalmente, el turismo de Toledo ha estado muy vinculado a Madrid por razones de proximidad, pero si esto ha sido siempre así, hoy lo es mucho más. La frecuencia de servicios interurbanos de autobuses con Madrid, cada media hora; la mejora de la comunicación por carretera con la capital de España y la puesta en servicio del AVE desde el 16 de noviembre de 2005, con 12 trenes diarios de ida y vuelta, facilitan los flujos de relación entre estas dos ciudades y dan protagonismo creciente a los desplazamientos de ocio y turismo que los visitantes de diferentes procedencias 
organizan y deciden libremente, sin que puedan ser cuantificados directamente por las estadísticas de los organismos oficiales de turismo. En todo caso, hay que tener en cuenta que muchos de los extranjeros y españoles de otras provincias que acuden a Madrid por diferentes razones, dedican por lo menos un día de su tiempo disponible a visitar Toledo, y que, por otra parte, los madrileños que se desplazan ocasionalmente allí para pasar el día, sobre todo durante los fines de semana, no dejan de aumentar.

Si se observa el cuadro $n^{\circ} 1$, en el que se muestra la evolución de los turistas que pernoctaron en Toledo desde el año 1999 hasta 2006, se puede comprobar como el incremento de los últimos tiempos ha sido relativamente importante; sobre el índice 100 en 1999, se ha pasado al índice 114 en 2006 (ligeramente por debajo de la media de aumento de las pernoctaciones en España que fue del 115), y de 615.702 personas que pernoctaron en la primera fecha, se ha pasado a 699.713 en la segunda. Este aumento de las pernoctaciones se corresponde con el notable crecimiento de la oferta hotelera en ese mismo periodo. Sin embargo, el peso de los extranjeros ha retrocedido considerablemente y su proporción respecto al total de turistas ha disminuido: del 30,9\% del año 2000, se ha pasado a los valores mínimos del 23,3\% en 2005 al $23,1 \%$ en 2006 , lo que no debe dejar insensible a los sectores económicos de la ciudad relacionados con el turismo y a los agentes públicos que son los principales responsables de su gestión.

En cambio, si se presta atención a la evolución de los visitantes que acuden en busca de información a las oficinas de turismo de Toledo, se comprueba que la proporción de extranjeros respecto al total de personas que entran en ellas se eleva hasta el $42 \%$, con una oscilación a lo largo del año que va desde unos mínimos del $24 \%$ en noviembre y el 33\% en febrero de 2006 a máximos del $56 \%$ en julio, el 52\% en junio y el $50 \%$ en mayo. Estos porcentajes de los visitantes extranjeros que demandan información, superiores respecto a los turistas también extranjeros que pernoctan, se explican por razones determinantes de las características del turismo toledano:

Cuadro 1. Pernoctaciones en la ciudad de Toledo.

\begin{tabular}{cccccc}
\hline Año & Españoles & Extranjeros & \% Extranjeros & Total & Crecimiento \\
\hline 1999 & 432.244 & 183.458 & 29,8 & 615.702 & 100 \\
2000 & 442.582 & 197.744 & 30,9 & 640.326 & 104 \\
2001 & 454.412 & 188.476 & 29,3 & 642.888 & 104 \\
2002 & 444.361 & 192.122 & 30,2 & 636.483 & 103 \\
2003 & 425.351 & 176.213 & 29.3 & 601.564 & 98 \\
2004 & 466.758 & 163.553 & 25,9 & 630.311 & 102 \\
2005 & 490.699 & 148.651 & 23,3 & 639.350 & 104 \\
2006 & 537.959 & 161.754 & 23,1 & 699.713 & 114 \\
\hline
\end{tabular}

Fuente: Elaboracón propia a partir de datos de la Encuesta de ocupación Hotelera. INE. 
la proximidad de Madrid y las facilidades de acceso desde la capital del Estado, lo que constituyen indudables ventajas pero, a la vez, graves inconvenientes, al menos de acuerdo con las estrategias actuales del turismo en esta ciudad (Troitiño, 2000). Una proporción muy alta de las personas de otros países que acude a Toledo, lo hace desde Madrid y sólo permanece unas horas en la ciudad imperial. Para gran parte de los turistas extranjeros que pasan por la capital de España, la visita de Toledo constituye una práctica de obligado cumplimiento, lo mismo que la visita del Museo de El Prado.

En cuanto a los españoles, el periodo de mayor frecuentación de la ciudad, como se observa en la figura 1, corresponde a los meses de abril, mayo y junio, coincidiendo con las mejores condiciones climatológicas y la celebración de los acontecimientos festivos y religiosos que intervienen como elementos especialmente significativos de atracción turística de Toledo: la Semana Santa ("Fiesta de Interés Nacional") y el Corpus Christi ("Fiesta de Interés Turístico Internacional"). Los otros máximos de visitas se registran en los meses de agosto, septiembre y octubre, aprovechando las

\section{Viajeros en Toledo 2006}

\section{№ de viajeros}

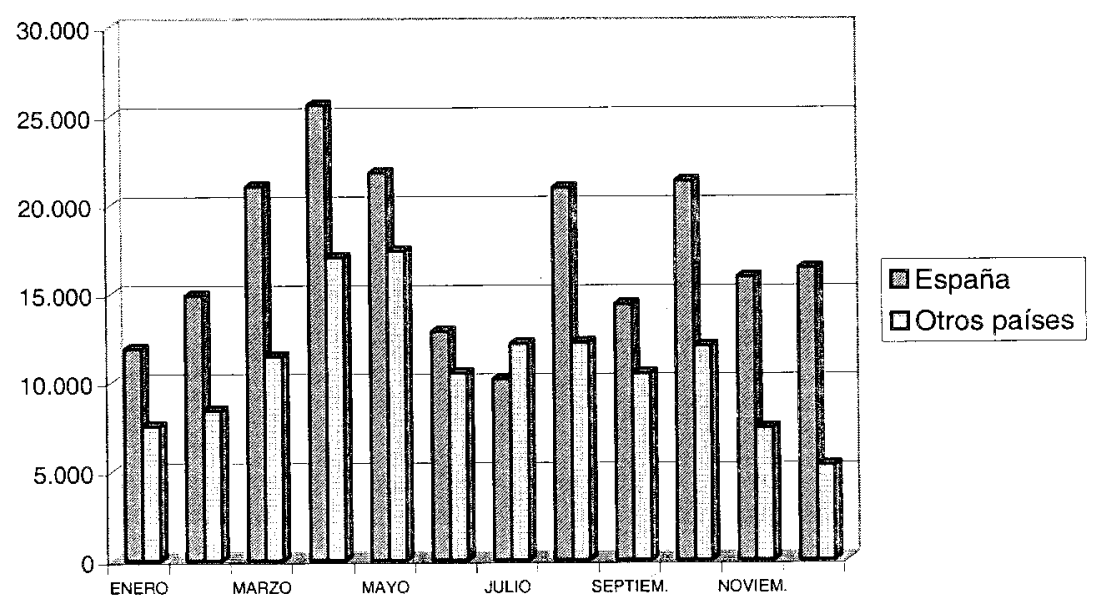

Figura 1. Evolución de los viajeros a lo largo del año. 
vacaciones estivales, las suaves temperaturas de otoño y las oportunidades de puente que, a menudo, proporciona la celebración de la Fiesta Nacional, el 12 de octubre. El comportamiento, como se puede apreciar en el mismo gráfico, es muy semejante para los extranjeros, dejándose también sentir en su curva de evolución anual un segundo máximo de frecuentación en los meses de julio y septiembre, en consonancia con las vacaciones estivales.

La importancia de Madrid para el turismo toledano se pone igualmente de relieve a través del análisis de los datos del Instituto de Promoción Turística de Castilla-La Mancha sobre procedencia por Comunidades Autónomas de los visitantes a esta ciudad en 2006 (Figura 2.). Madrid destaca ampliamente con el $21 \%$ del total, seguida de Andalucía, con el $16 \%$, y Castilla-La Mancha con el $13 \%$. El predominio de los madrileños se explica no sólo por la proximidad de Madrid respecto a Toledo, a sólo 70 kilómetros de distancia por carretera y con una magnífica comunicación mediante AVE, sino por el volumen de su población, más de 6 millones para el conjunto de la Comunidad, y por un comportamiento especialmente viajero. En 2006, según datos publicados anualmente por el Instituto de Estudios Turísticos, el 18,3\% de los viajes totales realizados por los españoles correspondió a los madrileños, seguidos de los catalanes, con el 16,3\%, y los andaluces, con el 15,1\%.

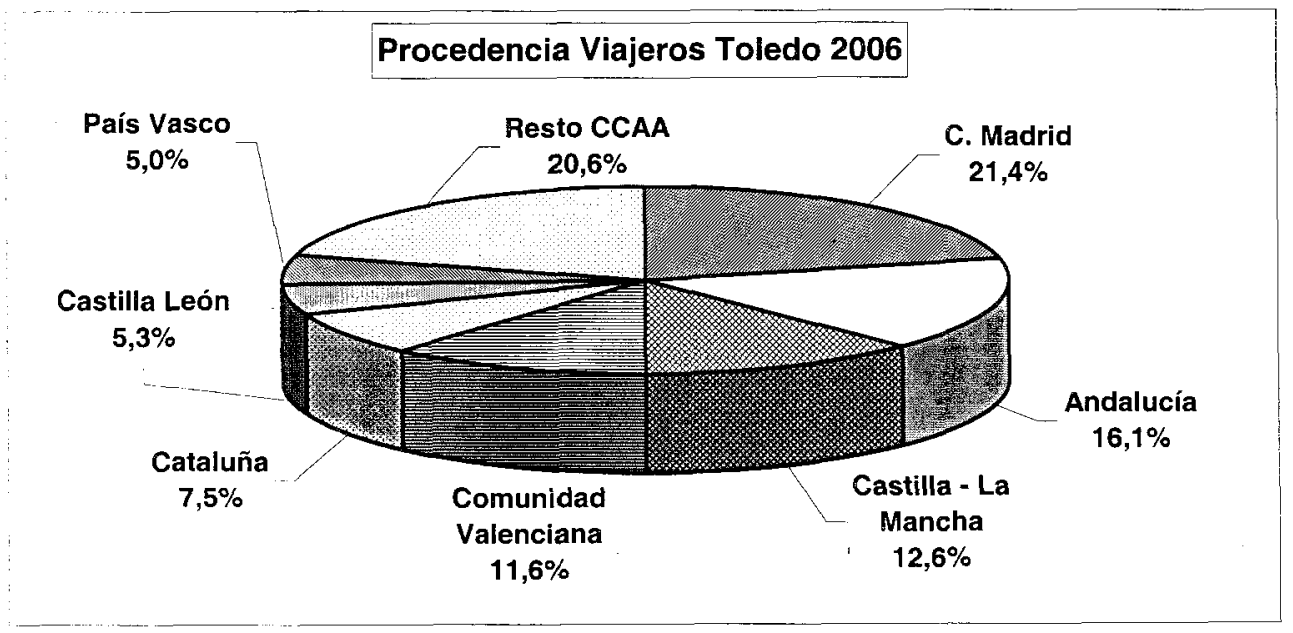

Figura 2. Procedencia por CCAA de los viajeros españoles. 
Por países de procedencia, los visitantes y turistas que acuden a Toledo, presentan una concentración considerable, pues el 62 \% llega desde Francia, Estados Unidos e Italia. Y dentro de ese $62 \%$, los franceses proporcionan el mayor porcentaje, con el $17,2 \%$ de los turistas extranjeros. En gran parte, ese hecho se explica porque los franceses ocupan el primer lugar entre los residentes en otros países que visitan Madrid y porque Toledo es visita prácticamente obligada para ellos como consecuencia de la aureola de prestigio que esta ciudad proyecta en Francia como lugar de interés turístico. Los motivos son muy variados, pero, a las razones culturales que derivan de la riqueza patrimonial de Toledo, se añaden las numerosas referencias de viajeros y escritores de esa nacionalidad y los fuertes vínculos que esta ciudad ha tenido con Francia a lo largo de la historia, sobre todo durante la Edad Media. Basta recordar como Constanza, la mujer de Alfonso VI, el rey que conquista la ciudad en 1086 para la Corona de Castilla, era francesa; como lo fueron también el primer obispo de la ciudad, Bernardo, los monjes benedictinos que constituyeron el primer cabildo catedralicio, y numerosos caballeros que formaron parte del sequito del rey, entre ellos los que se casaron con hijas suyas: D. Raimundo de Borgoña y D. Enrique de Lorena, y que tanta repercusión tuvieron para la historia peninsular. Además, los comerciantes francos fueron muy numerosos e influyentes en Toledo durante siglos, hasta el punto de definir la personalidad de un barrio toledano durante gran parte de la Edad Media, el "barrio de los francos", en torno a la iglesia de la Magdalena que todavía se conserva. Y aún se podrían citar otros muchos ejemplos para probar las estrechas relaciones que siempre ha habido entre Toledo y Francia.

Por otra parte, a los valores históricos y artísticos de la ciudad, que actúan como elemento principal de atracción turística, se suma la importancia creciente en este mismo sentido de los acontecimientos festivos más vinculados con su pasado. Otros elementos de atracción son los acontecimientos culturales relacionados con la música y el arte que tienen lugar cada vez con más frecuencia en Toledo, los primeros, en su mayor parte, en el Teatro de Rojas, y los segundos, en el Museo de Santa Cruz, y, de manera más ocasional, en otros espacios, como la Exposición de la Reina Isabel celebrada en la Catedral en 2006, aprovechando para ello la conmemoración del quinto centenario de su muerte y la terminación de importantes obras de restauración en su interior.

La infraestructura hotelera y de restauración de Toledo aumenta constantemente. En la actualidad, cuenta con más de 62 locales de alojamiento, 3.880 plazas hoteleras, 1.820 habitaciones de acogida y más de 100 restaurantes. Desde el punto de vista espacial, la concentración de hoteles y los restaurantes es muy fuerte, destacando tres espacios bien diferenciados: los Cigarrales, el Casco Histórico y los accesos al mismo, es decir los alrededores de la Plaza de Toros y las inmediaciones del puente nuevo de Alcántara, en la zona de contacto de los barrios de las Covachuelas y la Antequeruela, donde se ubican la estación de autobuses, dos grandes estacionamientos disuasorios y donde está prevista la apertura de un nuevo remonte a la ciu- 
dad antigua. En el caso de los restaurantes, la proporción de establecimientos de esta naturaleza en el Casco Histórico ha pasado del $50 \%$ en 1995 al $54 \%$ en 2006 y el aumento ha sido auténticamente espectacular en la zona de los Cigarrales, donde en 1995 sólo había 8 locales de restauración, el 8\% del total, y en 2006 ya había 16, el $15 \%$ del total.

En cuanto a los hoteles y plazas de alojamiento, el peso de los Cigarrales es también muy grande, con una oferta de 582 habitaciones en 2006, el $32 \%$ de todas las de la ciudad; su número es casi el mismo que el de plazas de alojamiento del Casco Histórico, 606, el 33\%. La tercera concentración espacial de hoteles, en los accesos al Casco Histórico, se apoya sobre la estación de autobuses y la entrada tradicional de la carretera de Madrid, en los alrededores de la Plaza de Toros y las inmediaciones del antiguo edificio del Hospital Tavera del siglo XVI (próximamente un nuevo hotel). A principio de los años 80 , todo esta zona empezaba a configurarse ya como una de las de mayor dotación funcional después del propio núcleo fundacional (Zárate, 1983).

En los mapas adjuntos de la ciudad, se han cartografiado dos indicadores de las tasas de función turística a escala de sección censal, el primero (Figura n³.) expresa la proporción de restaurantes por cada 100 habitantes en cada una de las unidades utilizadas como elemento de análisis y de referencia territorial, y el segundo (Figura $n^{\circ} 4$ ), la proporción de habitaciones de hoteles por cada 100 habitantes. De ese modo, se hace evidente la fuerte concentración espacial de la actividad turística en barrios y zonas muy concretas, siempre vinculada a factores de importancia monumental, valores paisajísticos y ventajas de accesibilidad. Respecto a esta última variable, a la influencia ya señalada de la carretera de Madrid y de la estación de autobuses en la concentración de hoteles en los accesos al Casco Histórico, se añade la

Cuadro 2. Restaurantes y habitaciones de hoteles por barrios.

\begin{tabular}{|c|c|c|c|c|c|c|}
\hline \multirow[b]{3}{*}{ Barrios } & \multicolumn{4}{|c|}{ Restaurantes } & \multicolumn{2}{|c|}{ Habitaciones } \\
\hline & \multicolumn{2}{|c|}{1995} & \multicolumn{2}{|c|}{2006} & \multirow[b]{2}{*}{$N^{0}$} & \multirow[b]{2}{*}{$\%$} \\
\hline & $\mathrm{N}^{\circ}$ & $\%$ & $N^{\circ}$ & $\%$ & & \\
\hline Sta María de Benquerencia & 11 & 11 & 3 & 3 & 0 & 0 \\
\hline Sta Bárbara & 5 & 5 & 4 & 4 & 119 & 7 \\
\hline Palomarejos y Buenavista & 10 & 10 & 8 & 8 & 40 & 2 \\
\hline Bloques y Sta Teresa & 17 & 17 & 7 & 7 & 104 & 6 \\
\hline San Martín y Cigarrales & 8 & 8 & 16 & 15 & 582 & 32 \\
\hline Acceso Casco Histórico & 0 & 0 & 10 & 10 & 369 & 20 \\
\hline Casco Histórico & 52 & 50 & 56 & 54 & 606 & 33 \\
\hline Total & 103 & 100 & 104 & 100 & 1.820 & 100 \\
\hline
\end{tabular}

Fuente: Elaboración propia. 
repercusión renovada con el AVE de la estación de ferrocarril para la ubicación hotelera en el paseo de la Rosa, enfrente de su bellísimo edificio neomudejar. A enorme distancia de las anteriores zonas de concentración hotelera, todavía podría citarse la representada por el borde del barrio de la Reconquista, en su lado más próximo al Centro Histórico. La construcción del remonte peatonal del paseo de Recaredo ha mejorado notablemente la conexión de esta parte de la ciudad con el Toledo histórico, aparte de funcionar como una vía de acceso para los visitantes de fin de semana que estacionan sus vehículos en el gran aparcamiento subterráneo construido al pie del mismo y junto a la muralla.

Por otra parte, la importante expansión de la infraestructura hotelera y de restauración en los últimos años debe de enmarcarse dentro del proceso espontáneo de aumento de movilidad de la población española desde ya hace décadas, en consonancia con el incremento de sus niveles de vida y de bienestar, con la transformación de la cultura en elemento de consumo de masas, la mejora de las comunicaciones con Madrid y el resto de Castilla-La Mancha, y las dinámicas generadas por la capitalidad de la región en Toledo. También hay que tener presente la influencia de unos procesos de globalización que se manifiestan en el seno de las actividades turísticas

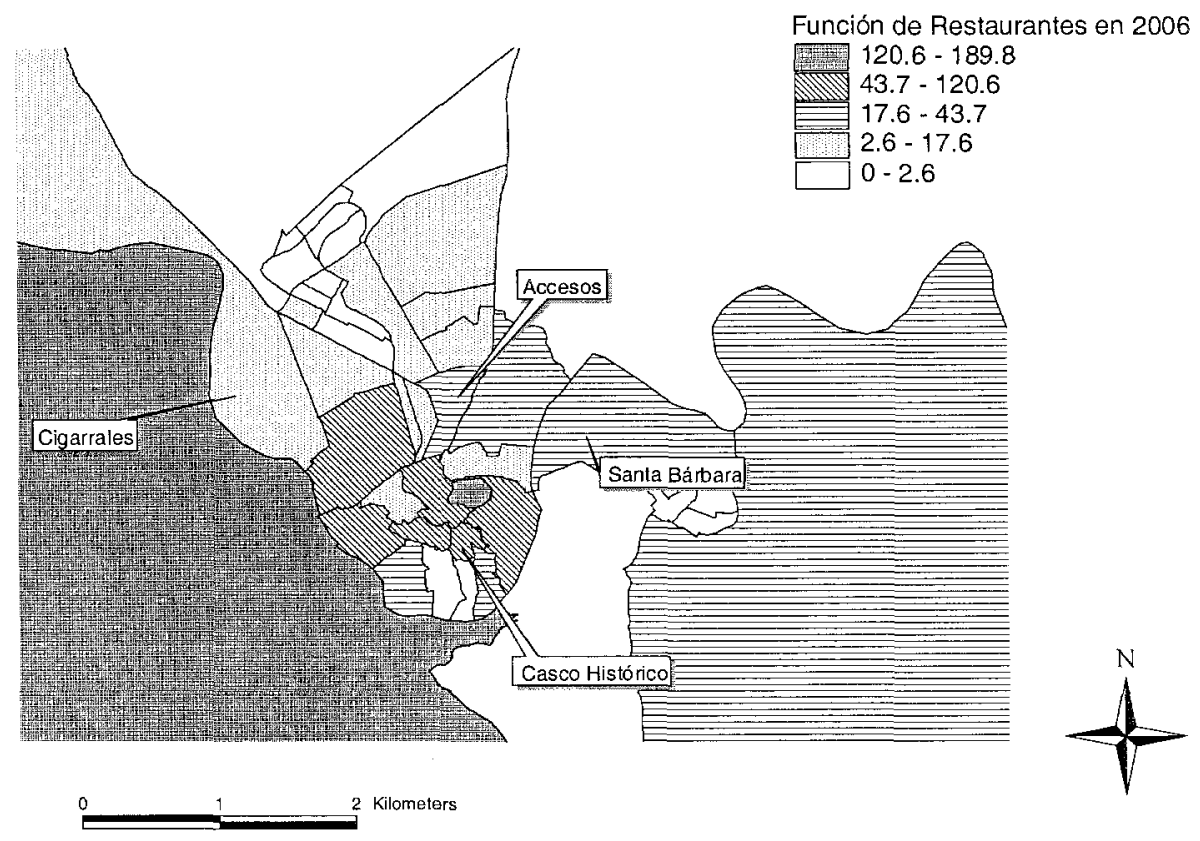

Figura 3. Distribución espacial de los restaurantes. 


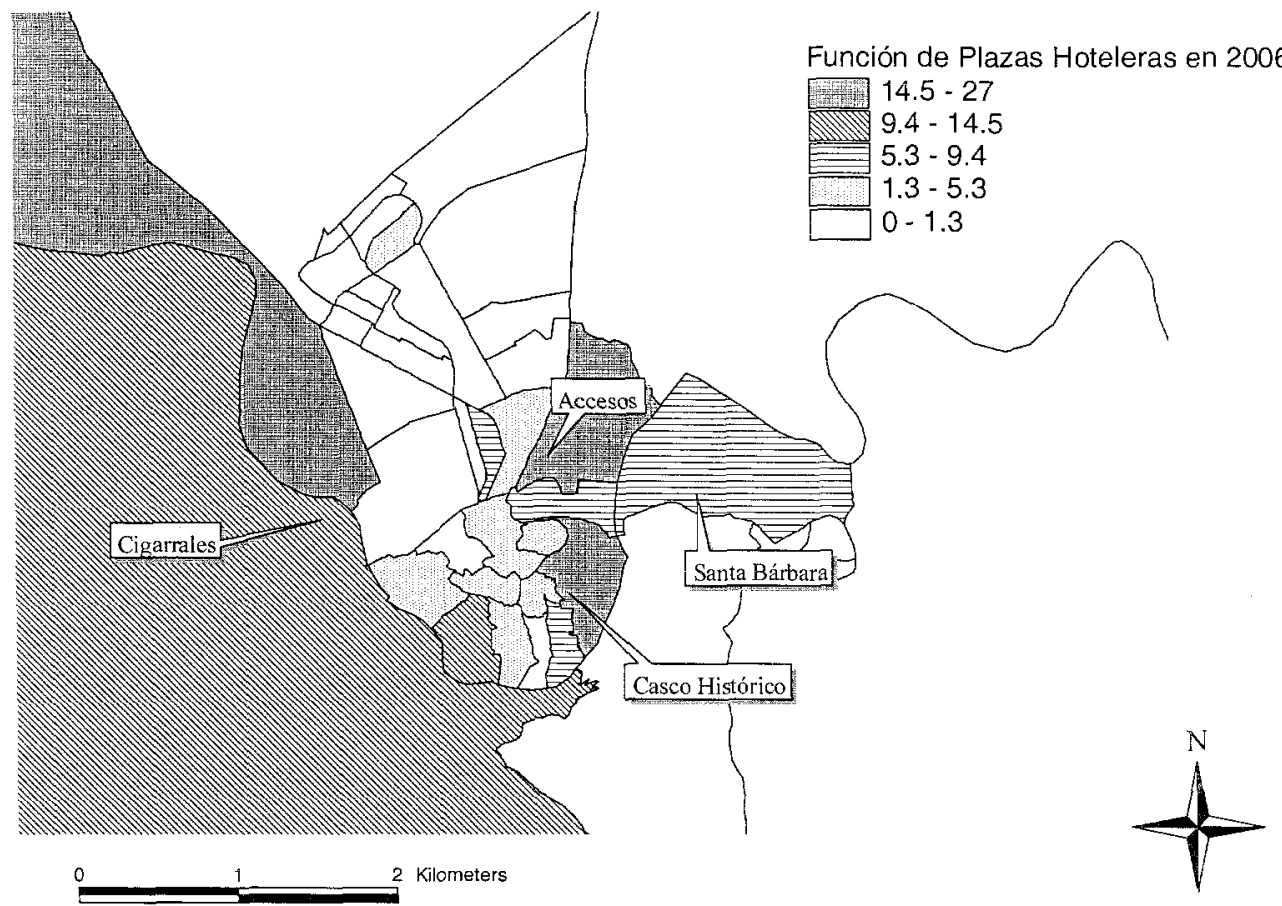

Figura 4. Distribución espacial de la función hotelera.

Fuente: Elaboración propia.

como en el conjunto de la economía y, de manera muy decisiva, las políticas turísticas puestas en marcha por los actores públicos y privados del sector.

En cuanto a los monumentos más frecuentados y dentro de las notables insuficiencias estadísticas al respecto, las visitas se concentran excesivamente en unos pocos, 6 concretamente, la mayoría dentro de unas rutas bien definidas por "turoperadores" que desde los años 60 controlan casi exclusivamente el turismo extranjero de agencia, y que ahora siguen teniendo considerable protagonismo. Cualquier fin de semana, es fácil observar riadas de turistas siguiendo unas mismas calles y entrando en unos mismo monumentos: la Catedral, el Museo de Santa Cruz, la Iglesia de Santo Tomé para contemplar el Entierro del Conde de Orgaz de El Greco, la Casa del Greco, las Sinagogas del Tránsito y de Santa María, y el Monasterio de San Juan de los Reyes. Fuera de esas calles, la tranquilidad es grande, los monumentos susceptibles de visitarse, numerosísimos, y los itinerarios posibles, infinitos. Por eso, una de las estrategias locales de desarrollo turístico consiste en dar a conocer esos monumentos y organizar rutas alternativas a las más frecuentadas por el turismo convencional, en este último caso con una participación decisiva del Consorcio de Toledo. 


\section{Los actores públicos del turismo}

En un contexto en el que el turismo es un elemento importante de crecimiento económico y de dinamismo social, las administraciones públicas se esfuerzan por participar en su desarrollo, aunque de manera desigual y siempre con el Ayuntamiento como responsable principal a través de la concejalía de turismo y de la oficina municipal de turismo. Como en otras ciudades, el Ayuntamiento ha utilizado los instrumentos legales propiciados por el "Plan Integral de Calidad del Turismo Español" (PICTE) para poner en marcha un "Plan de Calidad Turística", dirigido prioritariamente a sensibilizar a todos los agentes sociales del interés de esta actividad, y un "Plan de Excelencia Turística", que cuenta con la colaboración de la administración local, las autoridades de la provincia, el gobierno regional y los actores privados del turismo a través de la Federación de Empresarios de Toledo (FEDETO) y la Asociación de Empresarios de la Hostelería de la provincia de Toledo.

Entre los objetivos del "Plan de Excelencia Turística", presentado a principios de 2005 , tras un lento proceso de elaboración, destacan la "sostenibilidad" de la actividad turística, la mejora de la infraestructura de acogida, la diversificación de la oferta y el alargamiento de la estancia media de los turistas, ahora de día y medio, según la encuesta última publicada de ocupación turística del INE. Para alcanzar esos fines, los responsables locales estimulan la creación de nuevos servicios turísticos y argumentan la conveniencia de ofertar nuevos productos, siempre con la colaboración de la Federación de Empresarios Toledanos (FEDETO), la Junta de Comunidades y el Ministerio de Industria y Turismo, lo que en la práctica no resulta nada sencillo.

Dentro de los actores relacionados con el turismo toledano, se encuentran también la "Fundación Real de Toledo", creada por Real Decreto Ley 1424/1998 y puesta bajo la presidencia de honor del rey de España, y el "Consorcio de la ciudad de Toledo", organismo de carácter público, personalidad jurídica y capacidad de acción, del que el alcalde es su presidente. En la "Real Fundación", están representadas las administraciones local, provincial y regional, y su labor principal es la de ayudar en la coordinación de las inversiones que se reciben para la ciudad desde los diferentes niveles territoriales de la administración. También estimula la realización de obras, la creación de servicios e instalaciones en general, la mejora de los transportes y las comunicaciones, $y$, de manera muy especial, apoya iniciativas y proyectos culturales para la conservación del patrimonio histórico artístico y la extensión del papel de Toledo como lugar de encuentro de culturas diferentes. A su vez, el "Consorcio de la Ciudad de Toledo", en el que también están representadas las distintas administraciones, se encarga de las tareas de gestión de todos los asuntos anteriores y actúa como instrumento principal del Ayuntamiento para canalizar las ayudas económicas a la rehabilitación, incluidas las que conceden las diferentes administraciones a los particulares para operaciones de restauración, reforma, mejora de alojamientos y 
construcción en los sectores urbanos definidos como "Áreas de Rehabilitación Integradas" por el Plan Especial del Casco Histórico (Ayuntamiento de Toledo, 1997).

La preocupación por el turismo figura en las respectivas declaraciones de objetivos de la "Real Fundación" y del "Consorcio", si bien el mayor compromiso para el desarrollo de esta actividad corresponde al "Consorcio". Bajo su directa responsabilidad, se organizan visitas guiadas por lugares poco frecuentados pero de enorme valor histórico artístico, desde luego fuera de los itinerarios del gran turismo toledano. Se trata de nuevas rutas que se presentan bajo la denominación común de "Patrimonio desconocido", y se dirigen fundamentalmente a la puesta en valor de monumentos recuperados a través de misiones arqueológicas promovidas por el propio "Consorcio". Estas iniciativas comportan una elevada dosis de propaganda, pero representan también una aportación al descubrimiento de la ciudad por los residentes y los visitantes ocasionales. La publicidad sobre estas rutas está haciendo aumentar el número de turistas y visitantes que se apuntan a ellas, y más cuando se disponen en torno a monumentos y sitios de excepcional valor patrimonial, capaces de suscitar por sí mismo el interés de los posibles visitantes y con potencialidades más que suficientes para atraer al turismo de masas. Entre estas rutas, se encuentran las siguientes: Termas romanas de la plaza "Amador de los Ríos", Baños Árabes de "Tenerías", Baños Musulmanes "del Cenizal", Cuevas abovedas de la plaza de "EI Salvador", Torre de la iglesia de "San Román", Salas musulmanas del pasadizo cubierto "del Colegio de Doncellas" y "Grutas de Hércules".

Por otra parte, el Ayuntamiento se esfuerza por mejorar la acogida y la información de los visitantes. Para ello se ha decidido la creación de un gran centro de acogida en la entrada principal, en la carretera de Madrid. Su inauguración, prevista para 2004, se ha ido aplazando por razones presupuestarias y su construcción no terminará hasta 2007. El centro, de diseño aparatoso, mal integrado paisajísticamente y ubicado demasiado dentro de la ciudad actual, dispondrá de una oficina municipal de información y de un gran estacionamiento. Se ha previsto un servicio de lanzaderas que permitirá a los visitantes alcanzar el centro en muy poco tiempo y con una frecuencia de 10 minutos. En cuanto a la mejora de la información y la señalización para favorecer los desplazamientos de los turistas dentro de la ciudad, el Ayuntamiento ha multiplicado la instalación de planos en las principales encrucijadas del Centro Histórico y ha colocado paneles informativos delante de los monumentos más representativos.

La movilidad en el interior del Centro Histórico resulta harto complicada para cualquier persona por la naturaleza de su propio emplazamiento (un "peñón" rodeado prácticamente por el torno del Tajo), por los desniveles existentes dentro del mismo, por su entramado musulmán, con calles estrechas y proliferación de corrales y adarves, y por su gran extensión. El Centro Histórico de Toledo, con una superficie de 121,98 hectáreas, es uno de los más grandes de Europa y desde luego de España, sólo 
el de Sevilla es comparable por su tamaño. La mayoría de las calles del conjunto monumental son inadecuadas para la circulación automovilista, por lo que la política municipal apunta hacia la progresiva restricción del tráfico rodado, permitiendo por un número creciente de vías el paso sólo a residentes, el reparto de mercancías, la circulación de servicios de seguridad, limpieza y sanidad, y el acceso ocasional de turistas a los hoteles (Campos, 2000).

La inauguración de un aparcamiento subterráneo nuevo junto al Seminario, con plazas en rotación y para residentes, ha completado las previsiones de un total de 4 grandes estacionamientos públicos, más dos privados que existen desde fechas muy antiguas y que se saturan casi todos los fines de semana y siempre que existen acontecimientos festivos que concentran a residentes de otros barrios y visitantes de otros lugares dentro del recinto monumental. El acceso peatonal desde la ciudad moderna y desde la salida de un gran aparcamiento subterráneo en el Paseo de Recaredo, cerca de la Puerta de Alfonso VI y el Hostal del Cardenal, se realiza por una escalera mecánica que, aparte de su funcionalidad, se ha convertido en uno de los pocos símbolos de la modernidad de Toledo y en una solución afortunada para comunicar la ciudad histórica con unas de las zonas de la ciudad moderna.

Otro problema pendiente de resolver desde el punto de vista de la movilidad, y con clara incidencia en las posibilidades turísticas de Toledo, es el del estacionamiento de los autocares de servicio discrecional que prestan servicio a los "turoperadores" y transportan a diario hasta la ciudad a numerosos turistas. Su acceso al centro sólo se permite para subida y bajada de los turistas que se alojan en los hoteles próximos a la plaza de Zocodover y el Alcázar. Los autocares fletados por las compañías de viaje que llegan a diario desde Madrid para efectuar una visita guiada, son obligados a estacionar junto al puente de San Martín, en la orilla izquierda del Tajo. Allí se concentran grandes filas de autocares y desde ese lugar se desplazan riadas de visitantes que atraviesan el puente por las mañanas y regresan a la caída de la tarde para coger los autobuses de regreso hacia Madrid. En cambio, el acceso a la ciuclad de los autocares de líneas regulares, entre ellos los que unen la capital de España con Toledo cada media hora, se halla perfectamente resuelto por una confortable estación central de autobús, también situada en las inmediaciones del Tajo, pero en este caso cerca del puente de Alcántara y no lejos de la estación del AVE, donde el Plan de Ordenación Municipal, aprobado inicialmente por el Ayuntamiento el 3 de junio de 2006 y definitivamente por el Gobierno regional el 23 de marzo de 2007, ha previsto la creación de un nuevo ensanche (Orden 26/03/2007 de la Consejería de Vivienda y Urbanismo, D.O.C.M. no 67 , de 29 de marzo de 2007).

Para ofrecer a los visitantes una aproximación cómoda a la historia de la ciudad y permitirles disfrutar de sus bellos panoramas y magníficos paisajes, existe un tren turístico semejante a los que hay en la mayoría de las ciudades turísticas. En Toledo, el Ayuntamiento ha sido el promotor de este transporte, aunque su gestión ha sido 
otorgada a una empresa privada en forma de concesión del servicio. También se cuenta con dos nuevos elementos para favorecer la movilidad de los visitantes: un servicio de préstamo gratuito de bicicletas a cargo de la empresa concesionaria del estacionamiento del Alcázar, apenas utilizado por las características topográficas de la ciudad histórica y su entramado, y el alquiler de vehículos eléctricos monoplazas de dos ruedas que exigen el acompañamiento de un monitor y el desplazamiento en pequeños grupos.

La movilidad de los turistas discapacitados y de más edad no es objeto de una atención específica de las autoridades ni del resto de los agentes turísticos, a diferencia de lo que empieza a ser habitual en los entornos más turísticos de otros países. La atención a los desplazamientos de los discapacitados y de las personas de mayor edad es la que se deriva exclusivamente de las legislaciones del Estado y de la Junta de Castilla-La Mancha, que, como en todas partes, se esfuerzan por garantizar la seguridad y la movilidad de estos colectivos (autobuses de suelo bajo y plataformas para facilitar la subida y bajada, mobiliario urbano adaptado a sus necesidades, desaparición de barreras arquitectónicas, etc.).

Por último, las administraciones multiplican sus esfuerzos por mejorar la información y la comunicación a distancia de la ciudad, si bien todavía queda mucho por hacer. En este sentido, sorprende comprobar como la información que se facilita a través de los portales institucionales en Internet, o a través de otros muchos vinculados con actividades propiamente turísticas, se encuentra en español o en el mejor de los casos en inglés, pero nunca en francés y menos en otros idiomas, si se exceptúa el hecho, hoy por hoy un tanto paradójico y sorprendente teniendo en cuenta los flujos turísticos actuales del exterior hacia la ciudad, de que la Junta de Castilla-La Mancha ha introducido alguna información turística en "mandarín". En lo referente a la ausencia del francés, este hecho indica una falta importante de sensibilidad hacia el país que proporciona el mayor número de turistas y visitantes extranjeros, como se puede apreciar en el cuadro $n^{\circ} 3$.

\section{Los actores privados del turismo}

La importancia económica del turismo justifica el interés creciente de las asociaciones de empresarios locales por esta actividad y, consecuentemente, de la Cámara de Comercio e Industria de Toledo, en la que todos ellos se hallan representados. Dentro de la "Federación de Asociaciones de Empresarios de Toledo" (FEDETO), la "Asociación de Hoteleros y Restauradores de la provincia de Toledo" se muestra especialmente interesada por promocionar actividades dirigidas a aumentar el número de pernoctaciones, puesto que el principal problema del turismo toledanos sigue siendo 
Cuadro 3. Procedencia de los visitantes extranjeros.

\begin{tabular}{lcc}
\hline Pais de procedencia & Nuimero & $\%$ \\
\hline Alemania & 7.060 & 5,5 \\
Argentina & 5.757 & 4,5 \\
Brasil & 4.642 & 3,6 \\
EE.UU. & 19.766 & 15,5 \\
Francia & 21.965 & 17,2 \\
Italia & 11.926 & 9,3 \\
Méjico & 7.469 & 5,8 \\
Portugal & 2.721 & 2,1 \\
Reino Unido & 5.113 & 4 \\
Otros & 41.431 & 32,4 \\
Total extranjeros & 127.850 & 100 \\
\hline
\end{tabular}

Fuente: Elaborado con datos de las oficinas de turismo de 2006.

la escasa permanencia de los visitantes, debido a la proximidad de Madrid y a la naturaleza del turismo toledano, que no ha cambiado esencialmente respecto a sus características, estructura y composición en 1995 (Zárate, A., 1995). Hace 12 años, la mayoría de los turistas eran madrileños que acudían masivamente los fines de semana o durante las fiestas de más renombre. Otros eran visitantes nacionales y extranjeros que en su mayor parte llegaban también desde Madrid. Sólo el turismo cinegético, muy importante en la provincia, mostraba una mayor independencia de la aglomeración madrileña por su origen, ya que procedía en una proporción muy elevada de otras provincias españolas e incluso del extranjero, sobre todo de Italia y Francia.

En 1995, la ocupación hotelera mensual oscilaba entre el $40 \%$ y el $65 \%$ y la estancia media era corta, poco más de un día, mientras la media nacional era de 5 . Los esfuerzos de los empresarios se han concentrado desde entonces en la creación de nuevos recursos turísticos y en la mejora de una oferta hotelera que ya era buena a mediados de los 90 , con un $68 \%$ de plazas de alojamiento en hoteles de 3 y 4 estrellas frente al $44 \%$ para el conjunto de España. Desde que se tomó mayor conciencia de la importancia del turismo a finales de los años 80 por parte de los agentes económicos de la ciudad y de fuera de ella, se vienen creando nuevos hoteles y las infraestructuras de restauración no dejan de mejorar y aumentar. El número de plazas hoteleras ha pasado de 1.991 en 1987 a más de 3.800 actualmente y, lo que es más importante, se ha hecho una decidida apuesta por la calidad que se materializa entre otras cosas en la creación reciente de cuatro hoteles de 5 estrellas, uno de ellos en la zona de los Cigarrales, rompiendo con todos los criterios vigentes de protección de paisaje por la enorme masa de su volumen construido, la naturaleza y color de los materiales empleados y la forma del edificio, a pesar de haber contado con las autorizaciones del Ayuntamiento y de la Junta de Comunidades. 
En esta misma línea, los empresarios de 9 hoteles y restaurantes de la ciudad decidieron en marzo de 2006 la creación de la marca "Cigarrales de Toledo" y la elaboración de un catalogo general que, con el lema "Elige con vista", describe las instalaciones de los establecimientos ubicados en la zona de mayor calidad medioambiental del municipio toledano, los Cigarrales, y da a conocer una amplia oferta de actividades y ocio. Mediante esta acción, los promotores privados del turismo pretenden dar valor añadido a la ciudad con una marca de calidad, "Los Cigarrales de Toledo", y así atraer a una clientela de niveles medios y altos de rentas, y aumentar el tiempo de estancia de los turistas.

Sin embargo, los resultados han sido menos favorable de los esperados, sobre todo en cuanto a la duración de las estancias en la ciudad. El tiempo de estancia media en 2006 sigue siendo bajo, de 1,5 días, inferior a las medias provinciales de Castilla-La Mancha (desde el mínimo de Ciudad Real con 1,6 días al máximo de Albacete con 2,0) y lejos de la media del conjunto de España que era de 3,2 días. Sólo la tasa de ocupación hotelera de ese mismo año es un dato relativamente bueno desde el punto de vista económico, el 50,4\%, por encima de las medias mensuales de ocupación de las provincias de la región castellano manchega (Cuadro $n^{\circ} 4$ ), aunque también por debajo de la media española, $54,8 \%$, y eso a pesar de que los hoteleros y empresarios del sector redoblan sus esfuerzos por aprovechar las ventajas de la proximidad de Madrid, el principal destino turístico español de interior, y por hacer de Toledo un punto capaz de atraer por sí mismo a un número creciente de viajeros.

A su vez, el cuadro n 5 muestra una ocupación mensual media de las plazas hoteleras bastante baja entre 1999 y 2006, aunque con oscilaciones que van desde los mínimos del $35 \%$ en los meses de enero de 2004 y 2005 a los máximos por encima del $70 \%$ en los meses de agosto de 1999, 2000, 2001 y 2004. Lo menos satisfactorio es que esos datos evidencian un descenso de las tasas de ocupación media anual a lo largo del periodo considerado. El hecho resultaría más que alarmante si no se jus-

Cuadro 4. Ocupación hotelera en las provincias de Castilla-La Mancha y en la ciudad de Toledo, 2006.

\begin{tabular}{lccccccccccccccc}
\hline & $\begin{array}{c}\text { Enero } \\
\end{array}$ & $\%$ & $\%$ & $\%$ & $\%$ & $\%$ & $\%$ & $\%$ & $\%$ & $\%$ & $\%$ & $\%$ & $\%$ & $\%$ & $\%$ \\
\hline Albacete & 22,2 & 32,7 & 32,2 & 33,7 & 42,4 & 42,2 & 41,0 & 37,7 & 45,0 & 39,5 & 31,6 & 27,7 & 35,7 \\
Ciudad Real & 19,6 & 25,6 & 26,8 & 34,8 & 29,6 & 30,4 & 35,3 & 35,1 & 33,5 & 34,3 & 29,4 & 23,8 & 29,8 \\
Cuenca & 23,8 & 27,0 & 27,7 & 46,1 & 29,6 & 33,4 & 35,7 & 43,8 & 43,4 & 34,9 & 30,1 & 31,5 & 33,9 \\
Guadalajara & 23,9 & 27,4 & 31,8 & 33,7 & 34,3 & 35,4 & 36,2 & 35,5 & 37,0 & 35,9 & 30,7 & 30,0 & 32,7 \\
Toleclo & 29,9 & 36,9 & 35,2 & 45,0 & 35,7 & 37,0 & 37,8 & 44,5 & 44,6 & 41,3 & 33,0 & 30,6 & 37,6 \\
Ciu. Toledo & 38,9 & 50,0 & 45,2 & 65,5 & 45,0 & 48,2 & 48,2 & 63,4 & 61,7 & 56,4 & 40,5 & 42,2 & 50,4 \\
España & 40,9 & 46,5 & 48,9 & 56,2 & 53,4 & 61,0 & 67,9 & 74,5 & 64,7 & 54,6 & 46,5 & 42,2 & 54,8 \\
\hline
\end{tabular}

Fuente: INE, 2007. 
tificara por el fuerte incremento de plazas hoteleras y la constante apertura de nuevos hoteles durante los últimos años, coincidiendo con otro fenómeno bastante reciente, la progresiva integración de los hoteles de la ciudad en grandes cadenas nacionales e internacionales del sector.

En el empeño por incrementar el tiempo de estancia en la ciudad y la ocupación hotelera, que sólo es alta los fines de semana y durantes las grandes fiestas, con una media anual del $68,4 \%$ en 2006 , participan todos los actores privados del turismo. Dentro de las iniciativas realizadas en ese sentido, destaca la creación del "Convention Bureau" por la Cámara de Comercio e Industria de Toledo, una oficina encargada de la gestión y comercialización de Toledo como destino de negocios. El "Convention Bureau", creado en 2003, es actualmente una realidad consolidada que se encarga de la selección, presentación y comercialización de servicios y de la puesta en marcha de programas adaptados a las necesidades de las reuniones de negocios y susceptibles de ser movilizados en todo momento. Como resultado de su actuación, en 2006 se organizaron 136 congresos, 440 convenciones y 1.059 jornadas de trabajo en las que hubo un total de 120.202 participantes, con los consiguientes efectos económicos sobre el conjunto de los sectores de economía de la ciudad y especialmente con los relacionados con la hostelería, la restauración y el comercio.

Del mismo modo que los hoteles y los restaurantes no dejan de aumentar a lo largo de los últimos años, los locales comerciales dedicados a la venta de recuerdos y de productos elaborados por talleres artesanales han experimentado un fuerte impulso; hoy existen más de 140 locales comerciales de esta naturaleza. Entre ellos

Cuadro 5. Tasa de ocupación de las plazas hoteleras.

\begin{tabular}{lcccccccc}
\hline Meses & $\begin{array}{c}1999 \\
\%\end{array}$ & $\begin{array}{c}2000 \\
\%\end{array}$ & $\begin{array}{c}2001 \\
\%\end{array}$ & $\begin{array}{c}2002 \\
\%\end{array}$ & $\begin{array}{c}2003 \\
\%\end{array}$ & $\begin{array}{c}2004 \\
\%\end{array}$ & $\begin{array}{c}2005 \\
\%\end{array}$ & 2006 \\
\hline Enero & 38,07 & 35,22 & 45,12 & 34,91 & 37,09 & 35,1 & 34,78 & 38,9 \\
Febrero & 49,49 & 40,92 & 42,88 & 39,93 & 41,87 & 39,81 & 46,00 & 50,0 \\
Marzo & 50,28 & 47,36 & 50,63 & 51,31 & 41,07 & 45,88 & 53,21 & 45,2 \\
Abril & 66,82 & 62,22 & 64,06 & 58,22 & 57,1 & 59,81 & 50,44 & 65,5 \\
Mayo & 66,16 & 57,85 & 55,9 & 55,08 & 52,76 & 52,46 & 55,61 & 45,0 \\
Junio & 61,27 & 51,88 & 53,55 & 51,83 & 52,14 & 54,11 & 47,19 & 48,2 \\
Julio & 53,86 & 56,6 & 55,92 & 54,42 & 51,78 & 50,5 & 45,97 & 48,2 \\
Agosto & 78,35 & 73,76 & 75,43 & 67,5 & 64,95 & 72,73 & 62,89 & 63,4 \\
Septiembre & 73,21 & 66,25 & 63,17 & 67,8 & 59,07 & 65,46 & 60,76 & 61,7 \\
Octubre & 68,97 & 66,5 & 60,88 & 53,94 & 56,72 & 59,9 & 57,79 & 56,4 \\
Noviembre & 51,55 & 52,37 & 49,18 & 43,09 & 40,79 & 40,65 & 44,63 & 40,5 \\
Diciembre & 44,61 & 44,75 & 37,46 & 41,15 & 39,61 & 40,58 & 42,46 & 2,2 \\
Media anual & 58,73 & 54,78 & 54,61 & 51,75 & 49,73 & 51,6 & 50,33 & 50,4 \\
\hline
\end{tabular}

Fuente: Encuesta de ocupación hotelera INE. 
sobresalen los especializados en la venta de espadas, armaduras, damasquinado, cerámica y confiterías. La mayoría de estos comercios se localiza en el casco histórico, en las calles más frecuentadas por el turismo y en los alrededores de los monumentos más famosos.

La Federación de Empresarios (FEDETO), la Cámara de Comercio y el Ayuntamiento favorecen la especialización comercial del centro histórico en productos artesanales y de calidad para el turismo y los visitantes y, además, esta especialización refleja los cambios funcionales de un centro histórico que durante décadas ha ido perdiendo de manera alarmante población, de 29.184 personas en 1950 a 10.924 personas en 2006. La función residencial ha sido sustituida en gran parte por actividades terciarias y los comercios más tradicionales, relacionados con las necesidades de la población, han ido desapareciendo de manera espontánea al perder su clientela. En este marco, y en un afán por recuperar la vitalidad del núcleo funcional de la ciudad, la administración estimula la rehabilitación de antiguos locales comerciales y concede ayudas para abrir galerías de arte. La última de estas medidas es el compromiso del Consorcio de la Ciudad de Toledo para financiar hasta el $50 \%$ de las obras en comercios del Casco histórico, según resolución del mes de mayo de 2007 recogida en el Boletín Oficial de la Provincia de Toledo. De este modo, se avanza en la renovación del comercio en beneficio de actividades vinculadas con el turismo y con empresas multinacionales de la moda que buscan las mejores localizaciones en el centro histórico, especialmente en la calle Ancha o del Comercio, intentando atraer a una doble clientela: la que constituyen los propios residentes y la que integran los visitantes que acuden a la ciudad de manera esporádica por diferentes razones, entre ellas el turismo y las administrativas.

Para favorecer las ventas de los productos tradicionales del artesanado de Toledo tratando de aprovechar las ventajas del turismo, la Cámara de Comercio y las Asociaciones de Empresarios han elaborado una guía comercial que se distribuye gratuitamente a los visitantes y turistas en todos las oficinas de información de la ciudad y en las recepciones de los hoteles. Es una iniciativa más para dinamizar el turismo, aprovechando las ventajas que han supuesto la inauguración de la línea de alta velocidad Madrid-Toledo en 2005 y la construcción de una autopista de peaje entre la capital castellano-manchega y la capital de España, puesta en servicio el 29 de diciembre de 2006.

Por último, la Cámara de Comercio y Turismo promociona el denominado "turismo de descubrimiento económico" o de "visita de empresa" como otra estrategia para ampliar y diversificar la oferta turística de Toledo. En este caso, se trata de aprovechar la existencia de un tejido industrial relativamente importante en la provincia que apuesta por la innovación y se interesa por abrir sus instalaciones al gran publico. Los empresarios muestran así los procesos de elaboración de sus productos, difunden los artículos que fabrican y aspiran a un aumento de ventas. Como resul- 
tado de esta iniciativa, se ha elaborado una guía de turismo industrial y se ha puesto en servicio una dirección en Internet, donde se recogen las empresas que participan de estas iniciativas y se señalan las condiciones para efectuar la visita de cada una de ellas. De nuevo, lo que se pretende es aprovechar la proximidad de la aglomeración madrileña para atraer a un número potencialmente importante de personas que se sentirian interesados por conocer estas empresas, aparte de las visitas organizadas que muchas de ellas ya ofrecen para grupos escolares y personas de la tercera edad (Zárate, 2006).

Por otra parte, toda estrategia de desarrollo del turismo pasa por la optimización de la acogida, lo que implica contar con la colaboración de los residentes y mejorar sus actitudes hacia los turistas. Se trata de evitar comportamientos contrarios al turismo que resultan relativamente frecuentes en ciudades especializadas en esta función, como Venecia, Florencia o Brujas, donde la presión turística es muy elevada y puede resultar agobiante, sobre todo en ciertos periodos o días (Borg y Gotti, 1995). En el caso de Toledo, distintas encuestas sobre la actitud de los vecinos hacia el turismo han revelado la existencia de sentimientos de rechazo por parte de numerosas personas hacia esta actividad, si bien, finalmente y en general, se imponen las actitudes favorables.

El propio " Plan de Excelencia Turistica " de la ciudad recomienda la necesidad de sensibilizar al conjunto de la población sobre la importancia del turismo. Se considera imprescindible emprender medidas para estimular las relaciones entre los residentes y los turistas y motivar la complicidad de todos los que trabajan en el sector turístico, con vistas a conseguir que la estancia de los viajeros en la ciudad resulte lo más agradable posible. En Toledo, los presidentes de varias asociaciones de vecinos encuestados por nosotros mismos a este respecto, se muestran favorables a la promoción turística del centro histórico, pero siempre que se pongan en marcha mecanismos de control que eviten los perjuicios de esta actividad para los residentes, sobre todo en lo referente a ruidos nocturnos, problemas de circulación, dificultades de estacionamiento y efectos más indirectos y no visibles, pero muy sensibles para la población, como son el encarecimiento de los bienes de consumo y de los restaurantes. Todos los entrevistados se muestran también de acuerdo sobre la existencia de algunos efectos positivos del turismo, entre ellos su repercusión en favor de la mejora de los equipamientos urbanos, y todos valoran los esfuerzos de la administración local por coordinar la puesta en turismo de la ciudad con las acciones culturales y las estrategias de rehabilitación del patrimonio histórico.

La participación de los habitantes en los acontecimientos festivos se produce de manera espontánea, al margen de cualquier estrategia de desarrollo turístico, pero en la práctica esa participación actúa como un elemento más de atracción turística y, a veces, de manera muy destacada, como sucede en el Corpus o la Semana Santa. Las asociaciones de vecinos y los organismos oficiales y privados intervienen de una u 
otra manera en esos acontecimientos y especialmente en el Corpus, que es el principal evento religioso de Toledo, con una antigüiedad que se remonta al siglo XIV. La preparación de esta fiesta durante varias semanas depende de la Iglesia y del Ayuntamiento, pero resulta más que fundamental la colaboración de la "Junta del Corpus", asociación consagrada de manera expresa a esa finalidad. Esta asociación es de carácter privado y se financia con las aportaciones voluntarias del vecindario, asume el adorno de calles y plazas, e interviene en la elaboración del programa semanal de fiestas y en la organización de una procesión que desde que la Iglesia decidió en1991 el traslado del día de su celebración del jueves, como era tradicional desde la Edad Media, al domingo, no ha dejado de estar envuelta en la polémica ciudadana. Para resolver este conflicto, armonizando respeto a la tradición y adaptación al calendario civil, se ha decidido por iniciativa del Ayuntamiento, la celebración de dos procesiones desde 2004, una el jueves y otra, el domingo, esta última con un carácter más oficial por ser la que cuenta con mayor presencia de autoridades civiles.

Los otros grandes acontecimientos festivos de la ciudad son la Fiesta de la Virgen del Sagrario, a mediados de agosto, y el Carnaval. Los hosteleros, restauradores y comerciantes participan en la organización de todos estos acontecimientos y colaboran con ellos financieramente. Por otra parte, la Federación de Empresarios de Toledo (FEDETO), consciente del valor de las celebraciones festivas y de los eventos como elementos de animación social y de atracción turística, apuesta por su multiplicación, en especial de aquellos que tienen o pueden tener una orientación cultural, aprovechando conmemoraciones de significado histórico: la conquista de la ciudad por Alfonso VI (1086-1986), el V Centenario del nacimiento de Carlos V (1500-2000), el Año de Cervantes (1505-2005), el Centenario de la muerte de la Reina Isabel, la España Visigoda y San Ildefonso, etc. Estas conmemoraciones se han utilizado ocasionalmente para la organización de exposiciones, espectáculos de luz y sonido, fuegos artificiales y representaciones escénicas, como la entrada triunfal del Emperador Carlos $V$ en Toledo. Todos estos actos, de naturaleza extraordinaria y de excepcionalidad en cuanto a su celebración en el tiempo, aprovechan los atractivos que representan siempre en sí mismos y, de una u otra manera, la espectacularidad que deriva del emplazamiento de la ciudad, la belleza de sus paisajes y la singularidad de sus monumentos.

En todos los casos señalados, se trata de acontecimientos que se dirigen al conjunto de lá sociedad, que buscan la participación de los ciudadanos, convirtiéndoles al mismo tiempo en espectadores y actores, pero, además, las actividades que motivan actúan como elementos de atracción de visitantes, por lo que repercuten en el aumento de los flujos turísticos, en el alargamiento de las pernoctaciones y en el incremento de los visitantes de un solo día. No sorprende, por lo tanto, su progresiva integración en las políticas de turismo urbano. 


\section{Conclusión: luces y sombras del turismo toledano}

En el contexto actual, Toledo funciona como un destino turístico realmente importante de interior, gracias fundamentalmente a la importancia de su patrimonio histórico, cultural y paisajístico, a la proyección internacional de su nombre y a su papel en la historia como crisol de diferentes culturas y aglutinante de la historia española en momentos representativos del pasado. La proximidad a Madrid, la mejora de las comunicaciones, la transformación de la cultura en un producto de consumo de masas y los factores inherentes a la globalización que se manifiestan en el aumento de la movilidad de la población y en la interrelación del tejido empresarial local, nacional e internacional, favorecen también el desarrollo del turismo en la ciudad. A su vez, las actuaciones de las instituciones públicas y de los agentes privados de la ciudad, la Cámara de Comercio e Industria y la Federación de Empresarios de Toledo (FEDETO) de manera muy significativa, resultan determinantes a la hora de poner en marcha iniciativas orientadas a la diversificación de la oferta turística, a aumentar la ocupación hotelera y a incrementar las pernoctaciones. Resultado de todas estas acciones son la constante ampliación de las infraestructuras de acogida y de ocupación del tiempo libre, así como la mejora de las infraestructuras y equipamientos urbanos, aunque alguno de ellos, como la construcción del "Palacio de Congresos y Exposiciones" acumula retrasos y se alarga excesivamente en el tiempo, a pesar del lugar tan emblemático en el que se va a construir, debajo del Paseo del Miradero, y del daño que su vaciado representa para la imagen de la ciudad, una impresionante herida en la roca que sirve de asiento a la vieja ciudad, en su fachada norte. Lamentablemente, ese enorme vaciado es la primera visión que reciben actualmente los viajeros que llegan de Madrid, sin entrar en la polémica sobre la conveniencia o no de un emplazamiento de esta naturaleza para un Palacio de Exposiciones y Congresos, bajo tierra, en lugar de lo que se hace en la mayoría de las ciudades, donde estas construcciones se utilizan de manera emblemática como símbolos de modernidad dentro de los tejidos urbanos.

La complejidad de las políticas turísticas y la variedad de actores que intervienen en ellas, justifican la importancia de contar con un "Plan de Excelencia Turístican como el que Toledo tiene actualmente, y la necesidad de proceder a su constante adecuación a circunstancias muy cambiantes por la propia naturaleza del turismo y las características de la vida urbana. En principio, este plan ha dado respuesta al deseo del Ayuntamiento de disponer de un instrumento legal para conseguir un modelo turístico que se pretende competitivo y sostenible, ligado a políticas de renovación de los destinos turísticos maduros, como es el caso del turismo urbano y cultural en general y de Toledo en particular (Troitiño, 2000). Sin embargo, la aplicación del «Plan de Excelencia Turística" está siendo irregular e incompleta en la práctica y muchas de sus propuestas no han pasado del papel a la realidad, quedando como propaganda o simple declaración de intenciones, de tal modo que las acciones más comprometidas 
con el desarrollo del turismo corresponden fundamentalmente a la Cámara de Comercio de Toledo y a los empresarios privados, en definitiva a los actores privados del turismo. Todos ellos promueven iniciativas orientadas a la diversificación turística, como celebración de congresos y exposiciones, utilización del recinto ferial, turismo gastronómico, enoturismo, golf, turismo de naturaleza, turismo de compras y "team building", es decir, actividades que buscan la participación de las personas dentro de programas como "Aprende en Toledo", "Explora Toledo" y "Outdoor".

No obstante, a pesar de los indudables avances experimentados por el sector en los últimos años, el turismo toledano tiene que superar problemas de investigación, gestión, organización y promoción que derivan en buena parte del escaso entendimiento y de la poca colaboración entre las instituciones públicas de las administraciones local, provincial y regional. Tampoco existen canales de comunicación fluidos entre estas administraciones y la Iglesia, cuyos monumentos, entre ellos la Catedral y San Juan de los Reyes, son los más visitados de la ciudad y constituyen los primeros elementos de atracción turística. La propia "Dirección General de Patrimonio y Cultura" carece simplemente de datos estadísticos sobre la frecuentación turística de estos lugares. Así, la insuficiencia estadística constituye evidentemente uno de los problemas importantes para gestionar con eficacia el turismo toledano y un inconveniente a la hora de poner en marcha o aplicar estrategias concretas dirigidas a racionalizar los flujos turísticos.

Hasta hoy, Toledo, a diferencia de la mayoría de las ciudades en las que el turismo es una actividad importante, carece de un dispositivo permanente consagrado a la observación económica y medición estadística del turismo y a la valoración de sus efectos desde todos los puntos de vista. Los temas relacionados con la organización y gestión del turismo se hallan excesivamente compartimentados entre los diferentes agentes políticos, sociales y económicos que detentan responsabilidades en el sector y sería imprescindible contar con un "laboratorio permanente de estudio y seguimiento del turismo en la ciudad". En las actuales circunstancias, los empresarios son quienes sufren más las carencias señaladas, por lo que, consecuentemente, deberían ser los primeros y más interesados en disponer de un dispositivo permanente de observación del turismo.

Por otra parte, la presión turística sobre determinados lugares dentro de la ciudad y la fuerte concentración de las visitas en unos pocos monumentos crean problemas de conservación y mantenimiento que pueden resultar difíciles de resolver y a esos hechos se añaden, lo que todavía puede ser más grave, los inconvenientes derivados de una excesiva puesta en turismo del casco histórico, en detrimento de otros usos del suelo y actividades de esta zona de la ciudad. La normativa del propio "Plan Especial del Centro Histórico" de 1997 estimula esta "turistificación", al permitir una aplicación laxa de ciertas normas de edificación en las tareas de rehabilitación, siempre que se trate de adecuar construcciones para hoteles y equipamientos de restau- 
ración, al contrario de lo que hace cuando se plantean obras de rehabilitación y de renovación para fines residenciales. Y si esto es así dentro del casco histórico, todavía lo es más en la zona de los Cigarrales, donde se ha permitido la proliferación de hoteles con volúmenes de construcción y usos de materiales que rompen con sus valores históricos y culturales, que alteran el paisaje tradicional y modifican el parcelario, a pesar de las normas de protección existentes.

Finalmente, y ello no deja de ser paradójico si se tiene en consideración la apuesta realizada por los agentes públicos y privados de la ciudad a favor del turismo, Toledo se halla ante una seria amenaza de pérdida de elementos de su patrimonio y de sus paisajes por la aprobación definitiva de un Plan de Ordenación Municipal (POM), el 26 de marzo de 2007 , que propone la urbanización de todo el fondo del valle del Tajo. La edificación de la Huerta del Rey y la Alberquilla, en la Vega Alta, ocasionará daños irreversibles al paisaje tal como ha llegado hasta nuestros días y provocará la desaparición de uno de los espacios de mayor calidad medioambiental y paisajística de la ciudad, que forma parte indisoluble de los valores que hicieron de Toledo merecedora del calificativo de "Ciudad Patrimonio de la Humanidad" en 1986.

En la Vega Baja, la Junta de Castilla La Mancha ha decidido la suspensión del PAU asi denominado y la sustitución de la urbanización prevista por un "Parque Arqueológico" que sacará a la luz los restos de lo que fue la capital de la España visigoda. La ciudad dispondrá de este modo de un elemento más de atracción turística, pero la posible urbanización de los terrenos más próximos a ese parque y al propio Circo Romano mediante otros dos PAU, el del Circo Romano y el del Cristo de la Vega, supondrá la eliminación de restos arqueológicos, puesto que la zona es exactamente la misma que la que la Junta ha decidido proteger y los daños al paisaje serán más que evidentes.

En ambos casos, la urbanización de la Vega Alta y de la Vega Baja pondrá fin a paisajes y perspectivas de la ciudad que han llegado hasta nosotros excepcionalmente bien conservados y que son citados reiteradamente por la literatura e inmortalizados por los grandes maestros de la pintura. Desde el punto de vista turístico, los organismos y las instituciones relacionados con esta actividad no se muestran sensibles a los perjuicios que la urbanización de las vegas provocará sobre las vistas tradicionales del conjunto de la ciudad y tampoco son conscientes de que esos daños, de carácter irreversible, podrán afectar al turismo como actividad económica. La Real Academia de Bellas Artes y Ciencias Históricas de Toledo, la Real Academia de Bellas Artes de San Fernando, Hispania Nostra, la Real Sociedad Geográfica e ICOMOS han alertando a la sociedad sobre estos peligros y sobre el riesgo de que Toledo pierda su calificación como "Ciudad Patrimonio de la Humanidad", lo que indudablemente supondría un grave perjuicio para una ciudad cuyo dinamismo y vitalidad se basa en buena parte sobre el desarrollo del turismo. 


\section{Bibliografía}

Ahmed, Z.U. (1991): "The influence of the components of a state's tourist image on product positioning strategery". Tourisme Mangement, $\mathrm{n}^{\circ} 12$, pp. 331-340.

Ayuntamiento de Toledo (1997): Plan Especial del Casco Histórico de Toledo. Director del Plan: J. Busquets

Ayuntamiento de Toledo / Banco Europeo de inversiones (2000): Plan Estratégico del Centro Histórico de Toledo.

Ayuntamiento de Toledo (2003): Plan de Ordenación Municipal de Toledo. Director del Plan: Mario Muelas.

Borg, J. y Gotti, G. (1995): Tourism and Cities of Art. The impact of tourism and visitors flow management in Aix-en-Provence, Amsterdam, Bruges, Florence, Oxford, Salzburg and Venice. Ed. UNESCOROSTE, Venecia.

Busquets Grau, J. (1996): Plan Especial del Casco Histórico de Toledo, Ayuntamiento de Toledo.

Calle, M. de La (2002): La ciudad bistórica como destino turístico. Ed. Ariel Turismo, Barcelona.

Cámara de Comercio e Industria de Toledo (2005): Guía de congresos, Convection Bureau, Toledo.

Campesino Fernández, A. J. (2003): "Planificación estratégica del turismo cultural en ciudades patrimoniales: calidad, innovación y sostenibilidad". En Turismo Cultural y Urbano. Ed. Tirant lo Blanch, Valencia.

Campos Romero, L. (2000): "Movilidad y preservación ambiental en las ciudades patrimonio: el ejemplo de Toledo". En Ciudades históricas: conservación y desarrollo, Castillo, M. A. (ed.), Ed. Fundación Argentaria y Visor, pp. 45-55.
Campos Romero, L. Coordinadora (2002): El turismo en Castilla-La Mancba: análisis y prospectiva. Ed. Servicio de Publicaciones de la Universidad de Castilla-La Mancha., Col. Estudios n $n^{\circ} 83$, Ponencias celebradas en las 1 Jornadas sobre Turismo Regional en Toledo, del 2 al 6 de abril de 2001.

Carta Internacional sobre Turismo Cultural. ICOMOS. Comité Científico Internacional de Turismo Cultural, México, 1999.

Castaño, J. M.: Sáez, A., García, S. y Crego, A. (2003): "Aproximación psicosocial a la motivación turística". Revista de Estudios Turisticos, Instituto de Estudios Turísticos, $\mathrm{n}^{\circ} 158$, pp. 5-43.

Comisión de seguimiento del plan de excelencia turística de Toledo (2005): El Plan de Excelencia Turistica de Toledo, 20002005, $94 \mathrm{pp}$.

Dévé, M. O. (2003): "Les clientèles du tourisme urbain". Cabier Espaces, n ${ }^{\circ} 78$,

Équipe Mit (2002): Tourismes. Lieux communs. Paris, Éd. Beli, coll. Mappemonde.

Gravari-Barbas, M. (2006): "La ville à lè̀re de la globalisation des loisirs". En Espaces, tourisme et loisirs, $\mathrm{n}^{\circ} 234$, pp. 48-56.

Gómez Ibáñez, J.A. y McCueu, G. M. (eds.) (1995): Revitalización del Casco Histónico de Toledo. Patronato Universitario de Toledo/Real Colegio Complutense de Harvard. Bolenger Publication/Creative Printing, Inc. USA.

Laguna García, M. (2005): "La celebración de eventos culturales como atractivos turístico en las ciudades históricas: Análisis del impacto econónico y turístico". En Estudios Turisticos, $\mathrm{n}^{\circ} 166$, pp. 65-96.

Lobo Monteros, P. (2001): Promoción y comercialización turística de las ciudades históricas españolas". Boletin del Instituto Andaluz del Patrimonio Histórico, $\mathrm{n}^{\circ} 36$, pp. $150-169$. 
Moptma (1994): Estudio de reordenación viaria y del transporte en el Casco Histórico de Toledo. Una experiencia piloto, Madrid, ETT.

Stock, M. (Coordination) (2003): Le Tourisme. Acteurs, lieux et enjeux. Éd. Belin, coll. Géographie, Licence- IUT, Paris, 304 pp.

Troitiño Vinuesa, M. Á. (1998): "Turismo cultural: Toledo". Actualidad Turistica Española en 1996, Madrid, AECIT, pp. 507-514

Troitiño Vinuesa, M. Á. y Prats, F. (1998): Toledo 21. Una estrategia turistica para una Ciudad Patrimonio de la Humanidad. Documento Propuesto. Cámara de Comercio e Industria de Toledo, Toledo.

Troitiño Vinuesa, M. Á.; Brandis, D.; del Río, I.; Calle, M., Gutiérrez, J.; Lobo, P., Martín, F. (1998): "Toledo: problemática e implicaciones urbanas del turismo". Eria, ${ }^{\circ}$ 47, pp.299-325.

Troitiño Vinuesa, M. Á., M. Á. (2000): "Ciudades históricas, turismo y desarrollo sostenible". En Ciudades bistóricas: conservación y desarrollo, Castillo, M. Á (ed.), Fundación Argentaria y Visor, Madrid.

Violier Ph. (1999): “Les acteurs du système touristique et leurs logiques spatiales". En: Ph. Violier (dir.): L'espace local et les acteurs du Tourisme. Éd. Presses Universitaires de Rennes, Rennes, p. 57-67
World Tourism Organization (2002): City, Tourism and Culture: The European Experience, World Tourism Organization, Madrid.

Zárate Martín, M. A. y Vázquez González, A. (1982): El casco bistórico de Toledo. Un espacio urbano vivo?. Ed. Zocodover, Toledo.

Zárate Martín, M. A. (1994): "España a través de los artistas". En Geografía de España, Ed. Instituto Gallach, Barcelona, Vol. 1, pp. 141-192.

Zárate Martín,, M. A. (1995): "Imagen y potencial turístico de un Centro Histórico singular, Toledo". En Los turismos de interior. Valenzuela Rubio, M. (coord.). Ed. Universidad Autónoma de Madrid, pp. 289-304.

Zárate Martín, M. A. (2000): "Toledo, Ciudad Patrimonio de la Humanidad". En Boletín de la Real Sociedad Geográfica, Tomo CXXXVI, pp. 137-184.

Zárate Martín, M. A. (2006): "Las ciudades españolas en la Era de la globalización". En El espacio geográfico español y su diversidad, Ed. Ministerio de Educación y Ciencia, Madrid, pp.91-131.

Zárate Martín, M. A. (2006): "La visite d'entreprise en Espagne. Une filière à développer". En Les Cabiers Espaces, n 92, pp. 35-38. 